\title{
Out-of-Pocket Expenditure on Medicines in Turkey
}

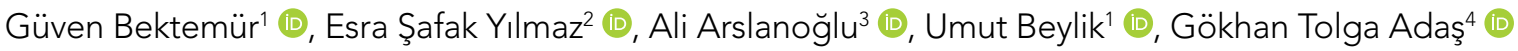 \\ 'Department of Health Management, Health Sciences University, İstanbul, Turkey \\ ${ }^{2}$ Turkish Medicines and Medical Devices Agency, Ankara, Turkey \\ ${ }^{3}$ Department of Quality Management, Health Sciences University Sultan Abdülhamid Han Training and Reseacrh Hospital, İstanbul, Turkey \\ ${ }^{4}$ Department of General Surgery, Health Sciences University Gaziosmanpaşa Taksim Training and Research Hospital, Istanbul, Turkey
}

Cite this article as: Bektemür G, Şafak Yılmaz E, Arslanoğlu A, Beylik U, Adaş GT. Out-of-Pocket Expenditure on Medicines in Turkey. JAREM 2018; 8(2): 101-8.

\begin{abstract}
Objective: The aim of this study was to determine the amount of out-of-pocket expenditure on medicines per year in Turkey and the proportion of this expense spend on domestically manufactured and imported medicines and that was covered under the Social Security System (SSS). In addition, by determining the variety of medicines used, the study aimed to investigate the type of medicines that dominates the out-of-pocket expenditure on medicines.

Methods: The data were obtained from the "Drug Tracking System (ITS)" database of the Turkish Pharmaceuticals and Medical Devices Agency. ITS is used for tracking and similar products. The data obtained from ITS were summarized and presented in tables. Calculations were performed using Microsoft Excel (Microsoft Office 365 ProPlus-tr), followed by ratio analysis.

Results: According to our findings, $16.4 \%, 18.6 \%$, and 19.2\% of the total spending on medications, was paid out-of-pocket in the January 2015 -December 2017. Regarding the number of boxes, $81.1 \%$ of the medicines paid out-of-pocket was domestically manufactured while $18.1 \%$ was imported between the same periods. In terms of monetary value in Turkish Lira, $59 \%$ of the medicines were domestically manufactured and $41 \%$ were imported. Of these medicines, $92.7 \%$ were covered by the repayment scheme of SSS, whereas 6.5\% were not. The proportion of drugs covered by the repayment system based on monetary value was approximately $80 \%$. According to the Anatomical and Therapeutic Chemical Classification System (ATC2) codes, antiinflammatory/anti-rheumatic, analgesic/anti-pyretic, and cold/cough medicines were the top three groups in sales based on the number of boxes; this ranking changed to urological, hormonal/genital system, and anti-inflammatory/anti-rheumatic medicines based on the monetary value.

Conclusion: According to the results of this study, the bulk of medicines purchased through out-of-pocket payment between 2015 and 2017 would be reimbursed by SSS, and most of these medicines were manufactured domestically. In terms of medicines diversity, anti-inflammatory/ anti-rheumatic medicines were the highest in terms of cost, whereas urological medicines were the highest in terms of the number of boxes based on ATC2 codes.
\end{abstract}

Keywords: Out-of-pocket expenditure on medicines, drug tracking system, sales of medicines

ORCID IDs of the authors: G.B. 0000-0001-5899-566X; E.Y.Ş. 0000-0003-2715-4600; A.A. 0000-0002-4454-0397; U.B. 0000-0002-4454-0397; G.T.A. 00000002-7777-8887.

\section{INTRODUCTION}

The health expenditures in the world show a tendency to increase due to several reasons such as the increase in elderly population, the diversity of medical devices and supplies coupled with technological developments, the increase in demands and expectations of the patients, the rise in the number of private hospitals, competition and quality consciousness, the enlargement in the scope of health coverage, and the change in the service encounter and payment models (1). Increased health expenditures exert serious pressure on the sources of limited health financing of the countries. Reducing and meeting the costs is one of the most important issues on which the states are working. Strategies to reduce the costs have been primarily designed to influence the supply and demand equilibrium belonging to the health care. For this purpose, different applications have been adopted to control the service size and cost, to plan the health expenditures such as limiting the package of basic care, the contributions of health consumer, the number of bed and personnel, and duration of hospital stay not to exceed a certain limit (2).
The financing system (3), which significant impacts the performance of a health system, is divided into three categories: revenue collection, fund pooling, and payment to service providers $(4,5)$. The type of financing of health services differs from country to country. Furthermore, even though the same method of financing is adopted, different outcomes may ensue in each country based upon the payment methods for health-care providers, the mode of organization of the health services, and the developing regulations for access to services (6).

The financing of health services is mainly covered by public and private sources. Public financing is based on the method of financing with social health insurance and taxes. General income and tax-based health system financing method is mentioned as it is a system in which the financing burden is spread throughout the society (7). Social health insurance aims to provide social justice (8), cover all segments of society with tax revenues, and ensure that everyone is protected from high health costs (9). Private financing (private health insurance system) consists of medical individual/family savings account and out-of-pocket 
expenditures. In this system, health-care services are the type of financing in which finance is undertaken directly by individuals, not by the public and employees, using health-care services (10). The medical savings account has highlighted the discussions on international health reform (11). It is based on the principle that individuals, household, and companies should voluntarily or mandatorily deposit money in their bank accounts in advance against the health risks they may face in the future, and use it only for health expenditures (12). Out-of-pocket expenditure method is the health-care spending method that is paid directly by the individual for using a health-care service. In this method, the financing burden of health-care services is partially or completely covered by individuals, and no other unit has any contribution (13).

The definition of payments for personal health services is generally "direct payments made by patients or households" $(14,15)$. Since out-of-pocket expenditures, one of the financing sources of health expenditures, can affect financial risk protection, financial equity, and the objectives of maximizing the health status of the society, it may negatively affect the health system performance of a country and thus the health status (16). In addition, the indiscriminate use of medicines taken by an out-of-pocket payment may lead to undesirable health risks.

Expenditures made in the out-of-pocket payment system are used for different items in the health service received. One of these items is the medicines that have an important place in medical treatment and care. In our country, the out-of-pocket expenditures for medicine are directly related to payment and contribution margin. These expenditures appear in four main structures:

1. Payments made by the person directly for the medicine required for his/her own treatment

2. Payments of contribution margin made by the person for the therapeutic medicines [In our country, contribution margin is paid as 10\% for Social Security Institution (SSI) employees and retirement pensioners and $20 \%$ for other institution employees]

3. Payments made by the person for the medicines depending on the outpatient treatment

4. Payment of the difference in the reference price determined by the government

The purpose of the study is to determine

a) Direct out-of-pocket expenditures made by the person for the medicines required for his/her own treatment in Turkey, which is the first of the above methods;

b) manufacturing/import, reference/equivalence rates of the medicines taken by out-of-pocket expenditure methods in our country; and

c) which types of medicines is more preferred by this method.

In this study, the data obtained from the "Drug Tracking System (DTS)" database of the Turkish Pharmaceuticals and Medical Devices Agency between 2015 and 2017 were used. The data were summarized and presented in tables with statistical information.

\section{METHODS}

\section{Data Source of the Study}

This is a retrospective study, and it has been prepared in accordance with Helsinki Declaration of human rights. In this study, the DTS database was used within the scope of cooperation protocol between Health Sciences University and Turkish Pharmaceuticals and Medical Devices Agency (TPMDA). This electronic structure has been established to define the locations of the drugs; their traceability are provided by QR codes; and it is possible to track via notifications to be received beginning from the production or importation to the each point they pass through. This structure includes a system that includes computers, database, and software for operating this database and communication infrastructures. The amount of drugs taken from pharmacies with SSI, other payment agents, and out-of-pocket expenditures are recorded on the basis of the number of boxes via DTS. Annual data between the years of 2015 and 2017 were used because it was the most recent data in this study. Data with no QR code matching are also shown in the tables.

\section{The Scope of the Research}

In Turkey, DTS has been planned by TPMDA to monitor medicines and similar products. Accordingly, this system also monitors all products included in the scope of "the Regulation Regarding the Packaging and Labeling of Medicinal Products for Human Use".

Hence, the products included in the scope of ITS are as follows:

- Prescription medicines: drugs prescribed for sale. These products are only available from pharmacies, and they require a medical prescription.

- Non-prescription medicines: drugs that can be obtained from pharmacies without a medical prescription.

- Medical nutrition products

All drugs monitored by DTS were included in this study without any drug group restriction.

\section{Statistical Analysis}

The data obtained from ITS were summarized and presented in tables. Calculations were performed using Microsoft Excel (Microsoft Office 365 ProPlus-tr), followed by ratio analysis. While calculating the medication prices, mid-year prices (June) were evaluated in terms of reflecting the average better.

\section{RESULTS}

When analyzing the medicines purchased through out-of-pocket expenditures, a proportional increase is observed each year, concordantly, SSI and other segments proportionately decrease every year. It was revealed that the ratio of medicines purchased through out-of-pocket expenditures was $16,4 \%$ in $2015,18,6 \%$ in 2016 , and $19,2 \%$ in 2017 . The ratio of medicines covered by SSI was found to be $82 \%$ in $2015,80,2 \%$ in 2016 , and $79,6 \%$ in 2017. The total purchase price of medicines was determined to be 1.670.015.824 boxes in 2015, 1.790.568.905 boxes in 2016, and 1.898.870.351 boxes in 2017 (Table 1).

On out-of-pocket expenditures, the purchase ratio of medicines domestically manufactured is higher than the amount of import- 
ed medicines each year and based on the total boxes. The ratio of medicines purchased through out-of-pocket expenditures and manufactured in Turkey was $81,7 \%$ in $2015,81,5 \%$ in 2016 , and $80,7 \%$ in 2017 . Additionally, the ratio of imported medicines was 17,5\% in 2015, 17,7\% in 2016, and 19\% in 2017 (Table 2).

Out-of-pocket expenditures for medicines manufactured in our country are higher than the amount of imported drugs each year and in total. However, there is no big difference between them as price/rate in terms of the number of boxes. It has observed that the ratio of the value of those manufactured in Turkey of the medicines purchased through out-of-pocket expenditures was $59,4 \%$ in $2015,59,8 \%$ in 2016 , and $57,9 \%$ in 2017 . The ratio of the value of imported medicines were found to be 40,4 in 2015, 40,2\% in 2016, and 42,1\% in 2017 (Table 3).

On out-of-pocket expenditures, the sales rate of medicines covered by the repayment system based on the number of boxes is higher than those are not on yearly basis and in total. The ratio of those not covered by repayment system of the medicines purchased through out-of-pocket expenditures was 6,5\% in 2015, $6,4 \%$ in 2016 , and $6,7 \%$ in 2017 . It was observed that the ratio of medicines covered by repayment system was $92,7 \%$ in 2015 , $92,9 \%$ in 2016, and 92,5\% in 2017 (Table 4).

The value-based sales rate of medicines covered by repayment system on out-of-pocket expenditures is higher than those are not on yearly basis and in total. The ratio of those not covered by repayment system of the medicines purchased through out-ofpocket expenditures was $19,8 \%$ in $2015,20 \%$ in 2016 , and $25,8 \%$ in 2017. The ratio of medicines covered by repayment system was found to be 80\% in 2015, 80\% in 2016, and 74,2\% in 2017 (Table 5).

The equipollency rate of medicines purchased through out-ofpocket expenditures in terms of the number of boxes is slightly higher than that of the reference medicines. The ratio of generic medicines purchased through out-of-pocket expenditures was $51 \%$ in $2015,52,5 \%$ in 2016 , and $52,3 \%$ in 2017 , whereas the ratio of reference medicines was $49 \%$ in $2015,46,6 \%$ in 2016, and 46,8\% in 2017 (Table 6).

The value-based rates of reference medicines on out-of-expenditures are higher than those of generic medicines. The value-based rate of generic ones of the medicines purchased through out-ofpocket expenditures was $37,4 \%$ in $2015,38,8 \%$ in 2016 , and $37,8 \%$ in 2017, whereas the value-based rate of reference medicines was $62,3 \%$ in 2015, 61,1\% in 2016, and 61,8\% in 2017 (Table 7).

The first 20 medicines purchased according to the Anatomical and Therapeutic Chemical Classification System (ATC2) codes used in the classification of drug were listed. Anti-inflammatory/ anti-rheumatic, analgesic/anti-pyretic, and cold/cough medicines took the third place based on the number of boxes (Table 8). Urological, hormonal/genital system, and anti-inflammatory/ anti-rheumatic medicines took the third place based on the monetary value (Table 9).

Table 1. Drug sales covered by out-of-pocket expenditures and by SSI based on the number of boxes by years

\begin{tabular}{|l|c|c|c|c|}
\hline $\mathbf{2 0 1 5}$ & Out-of-pocket expenditure & SSI & Other & Total \\
\hline & 272.975 .478 & 1.369 .622 .194 & 27.418 .152 & 1.670 .015 .824 \\
\hline \multirow{2}{*}{$\mathbf{2 0 1 6}$} & $16.4 \%$ & $82 \%$ & $1.6 \%$ & Total \\
\hline & Out-of-pocket expenditure & SSI & Other & 1.790 .568 .905 \\
\hline & 332.552 .979 & 1.435 .610 .583 & 22.405 .343 & $1.2 \%$ \\
\hline $\mathbf{2 0 1 7}$ & $18.6 \%$ & $80.2 \%$ & Other & Total \\
\hline & Out-of-pocket expenditure & $\mathbf{S S I}$ & 22.284 .540 & 1.898 .870 .351 \\
\hline
\end{tabular}

Table 2. The box-based rates of manufactured/imported medicines purchased through out-of-pocket expenditures in Turkey

\begin{tabular}{|l|c|c|c|c|c|c|c|c|}
\hline & $\mathbf{2 0 1 5}$ & $\mathbf{2 0 1 6}$ & $\mathbf{2 0 1 7}$ & \multicolumn{2}{c|}{ Toplam } & \multicolumn{2}{l|}{} \\
\hline $\begin{array}{l}\text { Manufactured/ } \\
\text { imported }\end{array}$ & Boxes & Percentage & Boxes & Percentage & Boxes & Percentage & Boxes & Percentage \\
\hline Manufactured & 223.051 .527 & 81.7 & 271.124 .442 & 81.5 & 291.908 .850 & 80.2 & 786.084 .819 & 81.1 \\
\hline Imported & 47.774 .169 & 17.5 & 58.825 .477 & 17.7 & 69.286 .530 & 19.0 & 175.886 .176 & 18.1 \\
\hline * & 2.149 .782 & 0.8 & 2.603 .060 & 0.8 & 2.901 .740 & 0.8 & 7.654 .582 & 0.8 \\
\hline Total amount & 272.975 .478 & 100 & 332.552 .979 & 100 & 364.097 .120 & 100 & 969.625 .577 & 100 \\
\hline
\end{tabular}


Table 3. The value-based rates of manufactured/imported medicines purchased through out-of-pocket expenditures in Turkey

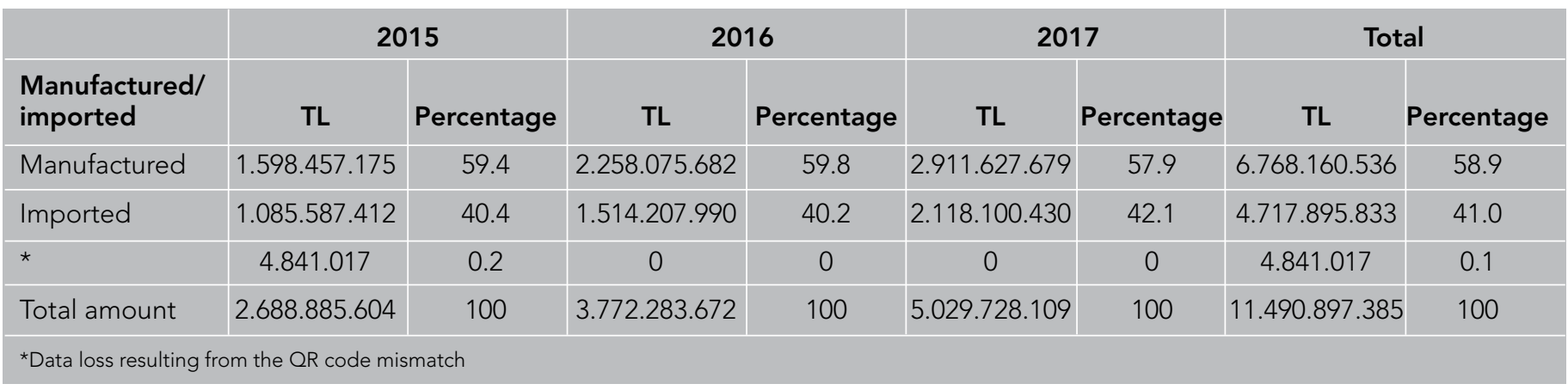

Table 4. The repayment rates of medicines purchased through out-of-pocket expenditures (box-based)

\begin{tabular}{|l|c|c|c|c|c|c|c|c|c|}
\hline & \multicolumn{2}{c|}{2015} & \multicolumn{2}{c}{2016} & \multicolumn{2}{c|}{2017} & \multicolumn{2}{c|}{ Total } \\
\hline & Boxes & Percentage & Boxes & Percentage & Boxes & Percentage & Boxes & Percentage \\
\hline $\begin{array}{l}\text { Not covered } \\
\text { by repayment }\end{array}$ & 17.790 .819 & 6.5 & 21.138 .188 & 6.3 & 24.543 .130 & 6.7 & 63.472 .137 & 6.4 \\
\hline $\begin{array}{l}\text { Covered } \\
\text { by repayment }\end{array}$ & 253.034 .877 & 92.7 & 308.811 .731 & 92.9 & 336.652 .250 & 92.5 & 898.498 .858 & 92.8 \\
\hline * & 2.149 .782 & 0.8 & 2.603 .06 & 0.8 & 2.901 .740 & 0.8 & 7.654 .582 & 0.8 \\
\hline Total amount & 272.975 .478 & 100 & 332.552 .979 & 100 & 364.097 .120 & 100 & 969.625 .577 & 100 \\
\hline *Data loss resulting from the QR code mismatch & & & & & & & \\
\hline
\end{tabular}

Table 5. The value-based repayment rates of medicines purchased through out-of-pocket expenditures

\begin{tabular}{|c|c|c|c|c|c|c|c|c|}
\hline \multirow[b]{2}{*}{$\begin{array}{l}\text { Manufactured/ } \\
\text { imported }\end{array}$} & \multicolumn{2}{|c|}{2015} & \multicolumn{2}{|c|}{2016} & \multicolumn{2}{|c|}{2017} & \multicolumn{2}{|c|}{ Total } \\
\hline & TL & Percentage & TL & Percentage & TL & Percentage & TL & Percentage \\
\hline $\begin{array}{l}\text { Not covered } \\
\text { by repayment }\end{array}$ & 532.796 .793 & 19.8 & 755.897 .743 & 20.0 & 1.030 .102 .775 & 25.8 & 2.318.797.312 & 20.2 \\
\hline $\begin{array}{l}\text { Covered by } \\
\text { repayment }\end{array}$ & 2.151.247.794 & 80.0 & 3.016 .385 .930 & 80.0 & 3.999 .625 .334 & 74.2 & 9.167 .259 .057 & 79.7 \\
\hline * & 4.841 .017 & 0.2 & 0 & 0 & 0 & 0 & 4.841 .017 & 0,1 \\
\hline Total amount & 2.688 .885 .604 & 100 & 3.772 .283 .673 & 100 & 5.029 .728 .109 & 100 & 11.490 .897 .385 & 100 \\
\hline
\end{tabular}

Table 6. The reference and generic rates of medicines purchased through out-of-pocket expenditures (box-based)

\begin{tabular}{|c|c|c|c|c|c|c|c|c|}
\hline & \multicolumn{2}{|c|}{2015} & \multicolumn{2}{|c|}{2016} & \multicolumn{2}{|c|}{2017} & \multicolumn{2}{|c|}{ Total } \\
\hline & Boxes & Percentage & Boxes & Percentage & Boxes & Percentage & Boxes & Percentage \\
\hline Generic & 139.406 .853 & 51.063 & 174.792 .440 & 52.563 & 190.599 .334 & 52.348 & 504.798 .627 & 52.061 \\
\hline THMP* & 4.030 & 0.001 & 3.228 & 0.001 & 14.176 & 0.003 & 21.434 & 0.002 \\
\hline Reference & 131.414 .813 & 49.153 & 155.154 .251 & 46.655 & 170.581 .870 & 46.850 & 457.150 .934 & 47.138 \\
\hline ** & 2.149 .782 & 0.783 & 2.603 .060 & 0.781 & 2.901 .740 & 0.799 & 7.654 .582 & 0.799 \\
\hline Total amount & 272.975 .478 & 100 & 332.552 .979 & 100 & 364.097 .120 & 100 & 969.625 .577 & 100 \\
\hline
\end{tabular}


Table 7. e value-based rates of reference and generic medicines purchased through out-of-pocket expenditures

\begin{tabular}{|l|c|c|c|c|c|c|c|c|c|}
\hline & \multicolumn{2}{|c|}{2015} & \multicolumn{2}{c}{$\mathbf{2 0 1 6}$} & \multicolumn{2}{c|}{2017} & \multicolumn{2}{c|}{ Total } \\
\hline & TL & Percentage & TL & Percentage & TL & Percentage & TL & Percentage \\
\hline Generic & 1.006 .344 .538 & 37.426 & 1.464 .303 .882 & 38.817 & 1.905 .683 .705 & 37.878 & 4.376 .332 .126 & 38.085 \\
\hline THMP* & 369.229 & 0.013 & 249.850 & 0.007 & 1.058 .053 & 0.021 & 1.677 .132 & 0.014 \\
\hline Reference & 1.677 .330 .820 & 62.381 & 2.307 .729 .940 & 61.176 & 3.122 .986 .351 & 62.101 & 7.108 .047 .111 & 61.860 \\
\hline ** & 4.841 .017 & 0.180 & 0 & 0 & 0 & 0 & 4.841 .017 & 0.051 \\
\hline Total amount & 2.688 .885 .604 & 100 & 3.772 .283 .673 & 100 & 5.029 .728 .109 & 100 & 11.490 .897 .385 & 100 \\
\hline * Traditional herbal medicinal product; **Data loss resulting from the QR code mismatch & & & &
\end{tabular}

Table 8. Top 20 rankings of drugs purchased by personal payment by ATC2 codes (box-based)

\begin{tabular}{|l|l|c|c|c|c|}
\hline & & $\mathbf{2 0 1 5}$ & $\mathbf{2 0 1 6}$ & $\mathbf{2 0 1 7}$ & Total \\
\hline ATC2 & ATC Name & Boxes & Boxes & Boxes & Boxes \\
\hline M01 & Anti-inflammatory and anti-rheumatic & 36.536 .540 & 44.918 .266 & 49.464 .531 & 130.919 .337 \\
\hline N02 & Analgesic/anti-pyretic & 34.143 .673 & 41.680 .158 & 42.826 .707 & 118.650 .538 \\
\hline R05 & Colds and cough remedies & 24.820 .112 & 31.732 .224 & 33.074 .355 & 89.626 .691 \\
\hline J01 & Antibacterial & 18.790 .911 & 19.175 .590 & 15.515 .301 & 53.481 .802 \\
\hline A02 & Stomach remedies & 9.672 .091 & 11.567 .925 & 12.606 .818 & 33.846 .834 \\
\hline B01 & Anti-thrombotics & 9.312 .791 & 11.003 .905 & 11.887 .048 & 32.203 .744 \\
\hline A11 & Vitamin drugs & 7.873 .896 & 11.311 .921 & 12.582 .052 & 31.767 .869 \\
\hline G03 & Sex hormones and genital system & 9.116 .046 & 10.712 .975 & 11.697 .917 & 31.526 .938 \\
\hline S01 & Drugs applied to the eye & 7.434 .790 & 9.094 .992 & 11.301 .750 & 27.831 .532 \\
\hline R01 & Nasal drugs & 6.476 .838 & 8.097 .316 & 9.184 .458 & 23.758 .612 \\
\hline N06 & Psychoanaleptics & 6.349 .229 & 7.767 .838 & 8.595 .713 & 22.712 .780 \\
\hline D01 & Treatment of dermatological fungi & 4.857 .010 & 5.969 .759 & 6.595 .341 & 17.422 .110 \\
\hline C09 & Drugs that regulate blood pressure & 3.663 .322 & 4.776 .358 & 5.914 .772 & 14.354 .452 \\
\hline R03 & Respiratory system occlusion & 3.400 .829 & 4.454 .188 & 5.193 .556 & 13.048 .573 \\
\hline A07 & Diarrhea drugs, intestinal anti-inflammatory and anti-infectives & 3.380 .885 & 4.321 .033 & 4.949 .566 & 12.651 .484 \\
\hline G04 & Urological drugs & 2.666 .094 & 3.576 .220 & 4.409 .118 & 10.651 .432 \\
\hline A10 & Diabetes & 2.303 .145 & 2.990 .385 & 3.535 .273 & 8.828 .803 \\
\hline H01 & Pituitary and hypothalamus hormones and analogs & 250.292 & 312.708 & 378.163 & 941.163 \\
\hline L04 & Immunosuppressive agents & 166.164 & 263.693 & 375.397 & 805.254 \\
\hline L01 & Antineoplastic drugs & 213.923 & 221.746 & 263.923 & 699.592 \\
\hline ATC2: Anatomical and Therapeutic Chemical Classification System & & & \\
\hline & (n) & & \\
\hline
\end{tabular}

\section{DISCUSSION}

In the majority of OECD countries, personal health expenditures have a very variable structure (17). The significant part of the health expenditures for people to raise or improve their health levels constitute expenditures on medicines or medical equipment (18). Out-of-pocket expenditures include physician examination fees, medical service purchase fees, and other health-related expenditures (19). When the reports published by the international organizations, especially the World Health Organization, the World Bank, and the OECD, on health expenditures are examined, in general, it has pointed out that the personal health expenditures are high in the OECD countries (20). According to the 2016 data of the Turkish Statistical Institute, in our country, $78,5 \%$ of health expenditures are covered by the general government budget, and $16.3 \%$ by households (21). 
Table 9. Top 20 rankings of drugs purchased by personal payment by ATC2 codes (value-based)

\begin{tabular}{|l|l|c|c|c|c|}
\hline & & $\mathbf{2 0 1 5}$ & $\mathbf{2 0 1 6}$ & $\mathbf{2 0 1 7}$ & Total \\
\hline ATC2 & ATC Name & TL & TL & TL & TL \\
\hline G04 & Urological drugs & 233.465 .120 & 348.815 .074 & 470.076 .859 & 1.052 .357 .053 \\
\hline G03 & Sex hormones and genital system & 218.864 .423 & 292.185 .442 & 397.244 .903 & 908.294 .768 \\
\hline M01 & Anti-inflammatory and anti-rheumatic & 195.279 .313 & 276.231 .195 & 380.620 .461 & 852.130 .969 \\
\hline R05 & Colds and cough medicines & 144.453 .499 & 215.498 .515 & 255.452 .374 & 615.404 .388 \\
\hline J01 & Antibacterial & 185.125 .373 & 205.721 .202 & 191.494 .910 & 582.341 .485 \\
\hline N02 & Analgesic/anti-pyretic & 105.428 .944 & 158.688 .310 & 221.715 .375 & 485.832 .629 \\
\hline A02 & Stomach remedies & 107.944 .032 & 153.532 .861 & 189.705 .033 & 451.181 .926 \\
\hline N06 & Psychoanaleptics & 96.505 .329 & 130.080 .357 & 169.008 .105 & 395.593 .791 \\
\hline L01 & Antineoplastic drugs & 80.013 .318 & 104.297 .503 & 160.545 .245 & 344.856 .066 \\
\hline S01 & Drugs applied to the eye & 65.569 .178 & 96.810 .020 & 136.746 .066 & 299.125 .264 \\
\hline C09 & Drugs that regulate blood pressure & 54.829 .790 & 77.547 .581 & 107.837 .265 & 240.214 .636 \\
\hline R03 & Respiratory system occlusion & 50.512 .467 & 81.536 .021 & 107.300 .639 & 239.349 .127 \\
\hline B01 & Anti-thrombotics & 49.256 .445 & 72.644 .510 & 104.586 .678 & 226.487 .633 \\
\hline A10 & Diabetes & 47.952 .869 & 68.909 .503 & 100.488 .679 & 217.351 .051 \\
\hline A07 & Diarrhea drugs, intestinal anti-inflammatory and anti-infectives & 42.414 .407 & 65.823 .488 & 100.776 .183 & 209.014 .078 \\
\hline D01 & Treatment of dermatological fungi & 45.892 .435 & 65.823 .756 & 78.921 .464 & 190.637 .655 \\
\hline H01 & Pituitary and hypothalamus hormones and analogs & 36.061 .017 & 64.286 .838 & 88.082 .272 & 188.430 .127 \\
\hline A11 & Vitamin drugs & 38.517 .688 & 57.042 .815 & 77.095 .824 & 172.656 .327 \\
\hline R01 & Nasal drugs & 40.193 .414 & 56.920 .361 & 73.486 .977 & 170.600 .752 \\
\hline L04 & Immunosuppressive agents & 24.402 .600 & 43.521 .531 & 73.632 .159 & 141.556 .290 \\
\hline ATC2: Anatomical and Therapeutic Chemical Classification System & & & \\
\hline & & & \\
\hline
\end{tabular}

Social Security Institution covers the large part of the total health expenditures of Turkey. One of the most important items of health expenditures financing provided by the institution is the financing of medication expenditures. Based on the 2016 data of the Ministry of Finance, the ratio of drug health expenditures in the public current health expenditures is predicted to be around $25 \%-30 \%$ according to the estimates of the next year (22). According to the findings obtained from this study, when we look at the box-based drug sales purchased through out-of-pocket payments and covered by SSI by years, it has been observed that the out-of-pocket expenditures that were 16\% in 2015 exceeded the level of $19 \%$ in 2017 . Within this framework, the portion of drug sales covered by SSI decreased from $82 \%$ in 2015 to $79 \%$ in 2017 (Table 1). Between the years 2015 and 2017, medicines purchased through out-of-pocket expenditures tend to be on medicines manufactured in Turkey rather than on imported medicines in terms of the number of boxes. This ratio was around $81 \%$ for manufactured medicines whereas around 18\% for imported medicines (Table 2). Considering that approximately $16 \%$ of general health expenditures are out-of-pocket expenditures, drug expenditures have a similar rate, and they have exceeded 19\% in recent years. The state's fixed wage and contribution margin policies for examination and medicines may be thought to have a signifi- cant impact on the behavior of the service providers. Contribution margins may provide a basis for drug use out of physician's recommendation and associated undesirable effects. In a study examined whether the contribution margin in Ghana has caused changes in the behavior of individuals' use of health service, it was determined that households prefer to treat themselves with medication because of the contribution margin required to pay for services such as outpatient examination, and this leads to delay in treatment (23). In Vietnam, it was determined that $67 \%$ of individuals with health problems have taken medication out of the physician's recommendation (24). Anti-inflammatory/anti-rheumatic, analgesic/anti-pyretic, and cold/cough medicines are the most common drugs purchased through out-of-pocket expenditures in Turkey, and they took the first three places based on the number of boxes (Table 8). The reason is that this group of drugs is prescribed once by the physician and are adopted by the patient, and this leads to a habit of purchasing these drugs directly from the pharmacy without referring to the doctor in recurrent complaints. Among the reasons that lead the patient to this habit are: these drugs are partially inexpensive, the total cost of the examination and drug contribution margin exceed the box price of the drug from time to time, or the patient is willing to pay the price of the drug by out-of-pocket payment in comparison with 
the price of the medication and the time and effort burden that the patient will spend in the health centers with health problems have taken medication out of the physician's recommendation (24). It has been found that urological, sex hormones/genital system, and anti-inflammatory/anti-rheumatic are the most common drugs purchased through out-of-pocket expenditures, and take the first three places in terms of monetary value in Turkish Lira (Table 9). Sexual-performance-enhancing drugs, specifically not covered by SSI, may be the cause of the elevation in the urologic group, and the contraceptive pill used by the public as a birth control method may also be the cause of the elevation in the sex hormones/genital system group. The fact that $81 \%$ of the drugs purchased through out-of-pocket expenditures in terms of the number of boxes are drugs manufactured in our country (Table 2) can be explained by the fact that the prices of these drugs are lower than the prices of the imported drugs. This situation seems to be an economic advantage for our country because the money does not go to abroad.

The antibacterial group drugs are in the fourth place in both tables $($ Table 8,9$)$ both on box basis and on value basis. The high rate of this drug group, which cannot be sold without prescription information, suggests that both physicians and citizens need to be more informed about rational drug use in our country.

The results of this study found that approximately $93 \%$ of the medicines purchased through out-of-pocket expenditures in the same period were covered by repayment system regarding the number of boxes, and approximately $47 \%$ of the medicines purchased were reference medicines whereas around $52 \%$ were generic medicines. The fact that whether the medicines are covered by repayment system has a little effect on the central buying. In particular, the primary factors include that commonly used medicines are manufactured in Turkey (anti-inflammatory/ anti-rheumatic, analgesic/anti-pyretic, cold/cough medicines. and antibiotics etc.), and are cheaper than imported medicines. Between the years of 2015 and 2017, 6.768.160.536 TL (per box: $8,6 \mathrm{TL}$ ) was paid for the total amount of 786.084 .819 boxes for the manufactured medicines, whereas 4.717.895.833 TL (per box: $26,8 \mathrm{TL}$ ) was paid for the total amount of 175.886 .176 boxes for the imported medicines on out-of-pocket expenditures. According to the study data, more than half of the medicines purchased through out-of-pocket expenditures were generic medicines. This indicated that the use of generic medicines has significantly increased in Turkey, and is also an important sign for their goaldirected use. Moreover, the issues such as sharing health-related matters in public by hearsay information and becoming a cultural element re-use of previously tried drugs, improper use, additional loss of access to health services in terms of time and cost can be considered as the main issues that can increase the central buying of the medicines.

\section{Limitations of the Research}

The data related to the medicines tracked by DTS are used. The products out of the scope of DTS are as follows:

- Products that can be used only in hospital environments such as dextrose, $\mathrm{NaCl}$ solution in serum form and high in versions,
- Radio-pharmaceutical products,

- Personalized products such as allergy vaccines,

- Magistral products,

- Data loss resulting from the QR code mismatch,

- Uninvestigated issue of why the medicines purchased through out-of-pocket expenditures are purchased by this method on an individual basis.

\section{CONCLUSION}

Since out-of-pocket expenditures, one of the financing sources of health expenditures, can affect financial risk protection, financial equity, and the objectives of maximizing the health status of the society, it may negatively affect the health system performance of a country and thus the health status. Out-of-pocket expenditures can cause people not to get the health services they need, and when they want to get it, they can face unpredictable expenditure risk and even impoverish them. In Turkey and other countries that have such as health-care system financing, the negative situations that may cause or contribute by out-ofpocket expenditures should be carefully evaluated. Since expenditures made with this method affect poor people more, financial risk protection programs such as medical savings accounts for these individuals, income based and individual risk plans, or even full or partial removal of out-of-pocket expenditures should be created. Of course, before such decisions are made, it should be taken into consideration which mechanisms will cover these lost expenditures, what additional problems may cause, and sustainability should be ensured without a social problem (16). In our country, although in general the sale of drug in pharmacies is not intended to make the sale of non-prescription drugs, in practice only the introduction of the prescription information for some drug groups in the system facilitates the purchase through outof-pocket expenditures method. In particular, urological medications, sex hormone/genital system drugs, anti-inflammatory and anti-rheumatism medications, which are paid the highest amount of value on the system, will lead to the prevention of misuse and health risks arising from the random use of these drugs.

Ethics Committee Approval: Authors declared that the research was conducted according to the principles of the World Medical Association Declaration of Helsinki "Ethical Principles for Medical Research Involving Human Subjects", (amended in October 2013).

Informed Consent: Informed consent was not required for his study.

Peer-review: Externally peer-reviewed.

Author Contributions: Concept - G.B., E.Ş.Y., A.A., U.B., G.T.A.; Design - G.B., E.Ş.Y., A.A., U.B., G.T.A.; Supervision - G.B., E.Ş.Y., A.A., U.B., G.T.A.; Resources - A.A., U.B., G.B.; Data Collection and/or Processing - E.Ş.Y., G.B.; Analysis and/or Interpretation - E.Ş.Y., G.B., A.A., U.A., G.T.A.; Literature Search - A.A., U.B., G.B.; Writing Manuscript - G.B., A.A., U.B., G.T.A.; Critical Review - G.B., G.T.A.

Acknowledgements: Thanks to Turkish Pharmaceuticals and Medical Devices Agency for its contrubutions.

Conflict of Interest: The authors have no conflicts of interest to declare.

Financial Disclosure: The authors declared that this study has received no financial support. 


\section{REFERENCES}

1. Yıldııım HH, Yıldırım T, Erdem R. Sağlık Hizmetleri Finansmanında Kullanıcı Katkıları: Genel Bir Bakış ve Türkiye Için Bir Durum Değerlendirmesi, Amme İdaresi Dergisi, 2011; 44: 71-98.

2. Hurst J. Challenges for health systems in Member Countries of the Organisation for Economic Co-operation and Development. Bulletin of the World Health Organization 2000; 78: 751-60.

3. Roberts MJ, Hsiao W, Berman P, Reich MR. "GettingHealth Reform Right. A Guide to Improving Performance and Eguity", Oxford Universty, Inc. 2004.

4. Mossialos E, Dixon A, Figueras J, Kutzin J, editors. Funding health care: options for Europe. 1steb. Philadelphia: Open University Press; 2002:1-31.

5. Gottret P, Schieber G. Health Financing Revisited-A Practitioners Guide, The World Bank, Washington, 2006. [CrossRef]

6. McCanne D. Health Care Systems-Four Basic Models; Physiciansf or a National Health Program (PNHP). Available from: URL : http://www. pnhp.org/single_payer_resources/health_care_systems_four_basic_models.php

7. Dixon A. Are medical saving accounts a viable option for funding health care? Croat Med J 2002; 43: 408-16.

8. Tatar M. Sağlık Hizmetlerinin Finansman Modelleri: Sosyal Sağlık Sigortasının Türkiye'de Gelişimi. Sosyal Güvenlik Dergisi 2011; 1: 103-33.

9. Carrin G, Waelkens MP, Criel B. Community-based health insurance In developing countries: a study of its contribution to the performance of health financing systems. Trop Med Int Health 2005; 10 : 799-811. [CrossRef]

10. Sekhri N, Savedoff W. Private health insurance: implications for developing countries. Bull World Health Organ 2005; 83: 127-34.

11. Hsiao WC. Medical Saving Accounts: Lessons From Singapore. Health Aff 1995; 14: 260-6. [CrossRef]

12. Deber RB, Forget EL, Roos LL. Medical savings accounts in a universal system: wishful thinking meets evidence. Health Policy 2004; 70 : 49-66. [CrossRef]
13. Güvercin A, Mil Hi, Tarım B. Sağlık Hizmetlerinin Finansmanı ve Sosyal Güvenlik Kurumu (SGK). Bartın Üniversitesi i.i.B.F. Dergisi 2016; 7.

14. What are the equity, efficiency, cost containment and choice implications of private health-care funding in western Europe? WHO Regional Office for Europe's Health Evidence Network (HEN) Report.2004.

15. Gaal P, Belli PC, Mckee M, Szocska M. Informal Payments For Healthcare: Definitions, distinctions and dilemmas. J Health Polit Policy Law 2006; 31: 251-93. [CrossRef]

16. Özgen H. Sağlık hizmetleri finansmanında cepten harcama: nedir? neden önemlidir? Hacettepe Üniversitesi Sağlık Idaresi Dergisi 2007; 10: 201-28.

17. Huber M, Orosz E. Health expenditure trends in OECD countries, 1990- 2001. Health Care Financ Rev 2003; 25: 1-22.

18. World Bank, Data and Statistics, Health Data. Available from: URL: http://data.worldbank.org/topic/health

19. World HealthOrganization, 2005. Distribution of Health Payments and Catastrophic Expenditures Methodology. Discussion Paper, Number2. Available from: URL: www.who.int/health_financing/documents/dp_e_05_2distribution_of_health_payments.pdf.

20. Çınaroğlu S. OECD’ye üye ülkelerde cepten sağlık harcamalarının hiyerarşik kümeleme analizi ile incelenmesi. Hacettepe Üniversitesi Sağlık Idaresi Dergisi 2015; 18: 47-60.

21. Sağlık Harcamaları İstatistikleri 2016. Available from: URL: http:// www.tuik.gov.tr/PreHaberBultenleri.do?id=24574.

22. Kamu ilaç harcamalarının 2016 yılı gelişimi ve 2017' den beklentiler. Available from: URL: https://www.medimagazin.com.tr/authors/ murat-ugurlu/tr-kamu-ilac-harcamalarinin-2016-yili-gelisimi-ve2017den-beklentiler-1-109-4012.html

23. Asenso-Okyere W, Anum A, Osei-Akoto I, Adukonu A. Cost recovery in ghana: are there any changes in health care seeking behaviour? Health Policy Plan 1998; 13: 181-8. [CrossRef]

24. Prescott N. Poverty, Social Services and Safety Nets in Vietnam. World Bank Discussion Paper,no 376. Washington: World Bank 1997. 